Document downloaded from:

http://hdl.handle.net/10251/68452

This paper must be cited as:

Ruiz Rico, M.; Fuentes López, C.; Pérez-Esteve, Ė.; Jiménez Belenguer, Al.; Quiles Chuliá, MD.; Marcos Martínez, MD.; Martínez-Máñez, R.... (2015). Bactericidal activity of caprylic acid entrapped in mesoporous silica nanoparticles. Food Control. 56:77-85. doi:10.1016/j.foodcont.2015.03.016.

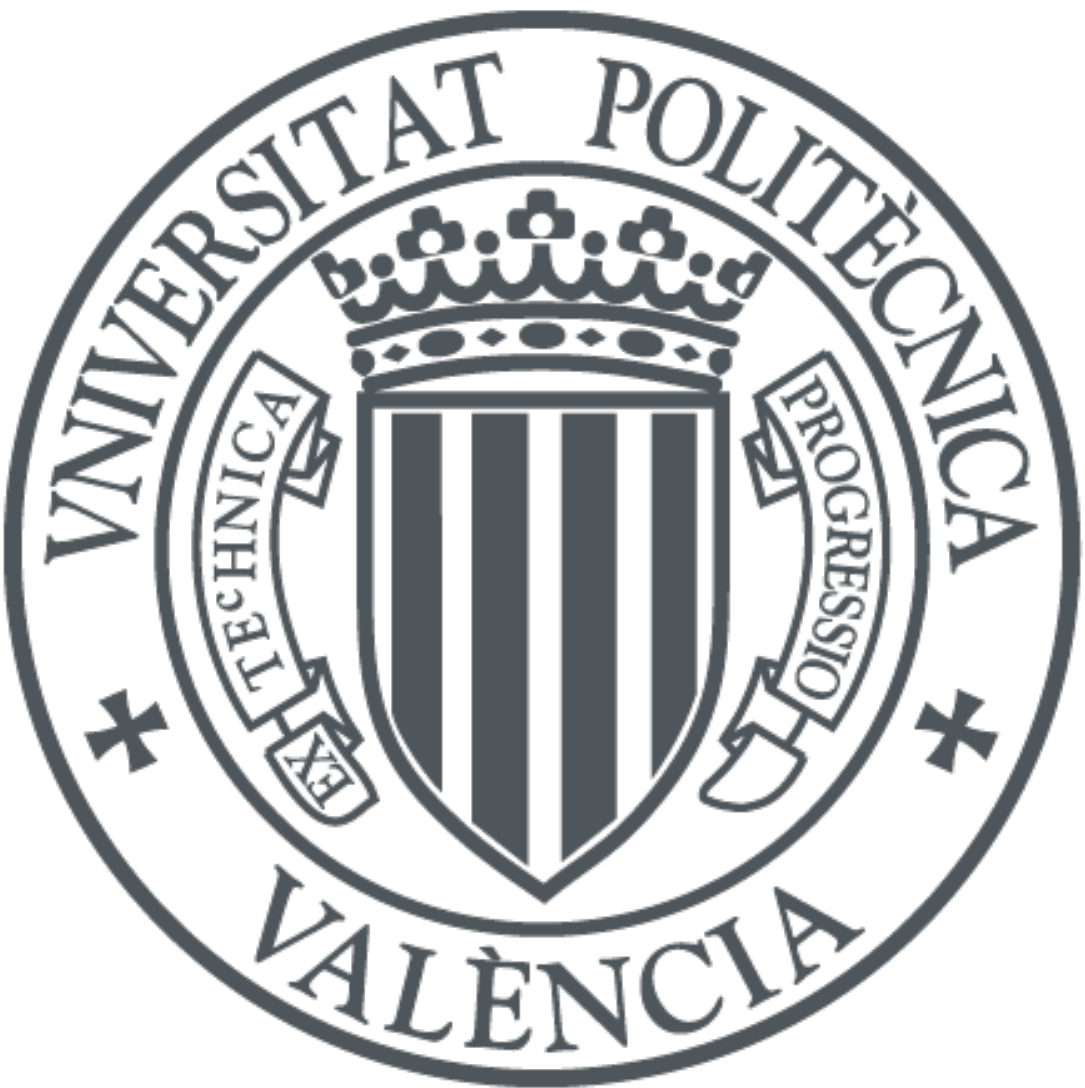

The final publication is available at

https://dx.doi.org/10.1016/j.foodcont.2015.03.016

Copyright Elsevier

Additional Information 


\section{Bactericidal activity of caprylic acid entrapped in mesoporous silica}

\section{nanoparticles}

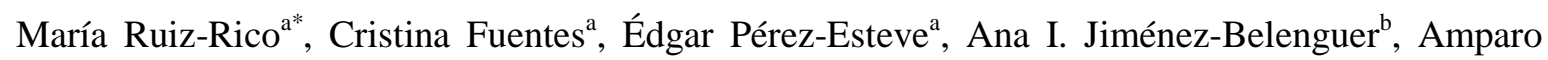
Quiles $^{\mathrm{c}}$, María D. Marcos ${ }^{\mathrm{d}, \mathrm{e}}$, Ramón Martínez-Máñez ${ }^{\mathrm{d}, \mathrm{e}}$, José M. Barat ${ }^{\mathrm{a}}$

${ }^{a}$ Grupo de Investigación e Innovación Alimentaria. Departamento de Tecnología de Alimentos, Universitat Politècnica de València. Camino de Vera s/n, 46022, Valencia, Spain

${ }^{\mathrm{b}}$ Departamento de Biotecnología, Universitat Politècnica de València. Camino de Vera s/n, 46022, Valencia, Spain

${ }^{\mathrm{c}}$ Grupo de Microestructura y Química de Alimentos. Departamento de Tecnología de Alimentos, Universitat Politècnica de València. Camino de Vera s/n, 46022, Valencia, Spain

${ }^{\mathrm{d}}$ Centro de Reconocimiento Molecular y Desarrollo Tecnológico (IDM), Unidad Mixta Universitat Politècnica de València - Universitat de València. Departamento de Química, Universitat Politècnica de València, Camino de Vera s/n, 46022, Valencia, Spain

${ }^{\text {e }}$ CIBER de Bioingeniería, Biomateriales y Nanomedicina (CIBER-BBN)

* Corresponding author: Phone: +34 963877000 ext.78258; E-mail address: maruiri@etsia.upv.es (M. Ruiz Rico). 


\begin{abstract}
Development of nanotechnologies to improve the functionality of natural antimicrobials for food applications has received much attention in recent years. Mesoporous silica particles, such as MCM-41, have been recently proposed as smart delivery devices capable of loading and releasing large amounts of cargo. In this study, the antimicrobial activity of caprylic acid entrapped in MCM41 nanoparticles against Escherichia coli, Salmonella enterica, Staphylococcus aureus and Listeria monocytogenes was tested and compared with the bactericidal effect of free caprylic acid using the macrodilution method. The minimum bactericidal concentration for free caprylic acid was established to be below $18.5 \mathrm{mM}$ for Staphylococcus aureus and Listeria monocytogenes and within the 18.5-20 mM range for Escherichia coli and Salmonella enterica. Moreover, caprylic acid - loaded nanoparticles showed a total inhibition of the growth within the 18.5-20 mM range for the tested bacteria, and therefore the antimicrobial activity was preserved. Transmission electron microscopy images revealed that bacteria treatment with the caprylic acid-loaded nanoparticles generated disruption of cell envelope and leakage of cytoplasmic content, which resulted in cell death. We believe that caprylic acid encapsulation in nanoparticles MCM-41 can provide an effective system for potential applications in food safety in the food industry due to the possible controlled release of fatty acid and the masking of its unpleasant organoleptic properties.
\end{abstract}

Keywords: Caprylic acid-loaded nanoparticles; antimicrobial activity; minimum bactericidal concentration; encapsulation 


\section{Introduction}

Antimicrobial agents are chemical compounds that are able to either inhibit the growth or inactivate pathogenic or spoilage microorganisms when present in or added to foods, food packaging, food contact surfaces or food processing environments (Weiss et al., 2009). Despite the effectiveness of these compounds, the continuous use of antimicrobials may result in the appearance of resistant strains (EFSA, 2013). Thus consumers are concerned about the safety of synthetic preservatives used in food. Consequently, demand for natural products or new administration forms that allow the concentrations of traditional antimicrobials to lower is increasing (Weiss et al., 2009; Gyawali \& Ibrahim, 2014).

In particular, natural antimicrobial agents have attracted much attention. However, the numbers of compounds allowed by regulations to be used in foods is very limited. Therefore it is necessary to make better use of available approved antimicrobial compounds and, for this reason, research has focused on developing technologies to help improve the functionality of food antimicrobials (Weiss et al., 2009).

Among various natural antimicrobial compounds, lipids, such as fatty alcohols, free fatty acids (FFAs) and monoglycerides of fatty acids, are known to be potent antimicrobial agents against enveloped viruses, bacteria and fungi (Hirazawa et al., 2001b; Chang et al., 2010). The antibacterial mechanisms of action of FFAs are still not completely understood, but the prime target seems to be the bacterial cell membrane via targeting various essential processes that occur within and on the membrane. In fact it is known that FFAs disrupt the electron transport chain and oxidative phosphorylation, inhibit enzyme activity, impair nutrient uptake, generate peroxidation and auto-oxidation degradation products, or directly lyse bacterial cells (Hirazawa et al., 2001a; Skrivanová et al., 2008; Desbois \& Smith, 2010; Chang et al., 2010; Solís de los Santos et al., 2010). In this context caprylic acid (CA), also known as octanoic acid, is an eight-carbon chainlength saturated FFA with reported antimicrobial activity. CA is found in the breast milk of various mammals and is a minor component of coconut oil and palm kernel oil (Hirazawa et al., 2001b; Jang \& Rhee, 2009; Chang et al., 2010). It is a food-grade compound classified and generally 
recognised as safe (GRAS) by the U.S. Food and Drug Administration, and is also considered safe by the Joint FAO/WHO Expert Committee on Food Additives when used as flavour (JECFA, 2000). For instance the effectiveness of free CA against food-borne pathogens, Escherichia coli, Listeria monocytogenes, Cronobacter spp., and Salmonella spp. in food has been reported (Nair et al., 2004; Vasudevan et al., 2005; Jang \& Rhee, 2009; Chang et al., 2010; Choi et al., 2013). Despite such evidence, the application or supplementation of food products with CA has disadvantages for its sensorial properties, such as an unpleasant rancid-like smell and taste (Hulankova et al., 2013), and diminished antimicrobial activity due to interactions with food constituents (Kabara et al., 1972). A suitable approach to address these problems can be the use of encapsulation supports which may allow FFAs to maintain their properties and increase stability against external agents. In fact nano-encapsulation has been reported to overcome some difficulties that emerge when applying antimicrobial compounds in their free form. Besides, reduction of particle size can improve delivery properties, solubility, residence time and absorption of bioactive compound through cells (Sozer \& Kokini, 2009). Therefore, some problems such as complex mass transport phenomena, interaction with food constituents or alteration of functionality due to physical and chemical food processes (Weiss et al., 2009) can be prevented.

Current nanostructured encapsulation systems for food applications are based on nanoemulsions, microemulsions, solid-lipid nanoparticles, micelles and liposomes (Sozer \& Kokini, 2009). One alternative to these nanostructured systems is mesoporous silica particles (MSPs). As supports for encapsulation and controlled release, MSPs such as MCM-n (Mobil Composition of Matter), exhibit unique features, such as high stability, biocompatibility, non-apparent toxicity, large load capacity and the possibility of including gate-like scaffoldings on the external surface (Aznar et al., 2009; Slowing et al., 2008; Al Shamsi et al., 2010; Suh et al., 2009; Manzano \& Vallet-Regí, 2010; Coll et al., 2013; Pérez-Esteve et al., 2014). Encapsulation of natural antimicrobial compounds in this type of particles has been recently reported (Park et al., 2012; Park \& Pendleton, 2012), and it offers promising results as a delivery support. 
The purpose of this study was to evaluate the antimicrobial activity of caprylic acid entrapped in mesoporous silica nanoparticles against some food-borne pathogens such as Escherichia coli, Salmonella enterica, Staphylococcus aureus and Listeria monocytogenes, and to study the morphological changes produced in the bacteria treated with the MCM-41 CA-loaded nanoparticles.

\section{Materials and methods}

\subsection{Chemicals}

Tetraethylorthosilicate (TEOS), N-cetyltrimethylammonium bromide (CTABr), sodium hydroxide $(\mathrm{NaOH})$ and caprylic acid (CA) were provided by Sigma (Sigma-Aldrich Química S.L., Madrid, Spain). N-hexane HPLC grade was supplied by Scharlau (Barcelona, Spain).

\subsection{Mesoporous silica particles synthesis}

Nanoparticulated MCM-41 particles were synthesised by following the procedure described by Bernardos et al. (2010). The molar ratio of the reagents was fixed at 1 TEOS:0.1 CTABr:0.27 $\mathrm{NaOH}: 1000 \mathrm{H}_{2} \mathrm{O}$. $\mathrm{NaOH}$ was added to the CTABr solution and the solution temperature was adjusted to $95^{\circ} \mathrm{C}$. TEOS was then added dropwise to the surfactant solution. The mixture was allowed to stir for $3 \mathrm{~h}$ to yield a white precipitate. After the synthesis the solid was recovered, washed with deionised water and air-dried at room temperature. The as-synthesised nanoparticles were calcined at $550^{\circ} \mathrm{C}$ in an oxidant atmosphere for $5 \mathrm{~h}$ to remove the template phase (N0).

\subsection{Synthesis of $\mathbf{N 1}$}

In a typical synthesis, $200 \mathrm{mg}$ of free-template solid (N0) were suspended in a solution of $5.7 \mathrm{~g}$ of $\mathrm{CA}$ in $19 \mathrm{~mL}$ of $\mathrm{n}$-hexane in a round-bottomed flask. The mixture was stirred for $24 \mathrm{~h}$ at room temperature to achieve maximum loading in the MCM-41 scaffolding pores. The loaded nanoparticles (N1) were isolated by vacuum filtration and dried at room temperature for $24 \mathrm{~h}$. 


\subsection{Materials characterisation}

The starting MSP (N0) and CA-loaded MSP (N1) were characterised by standard techniques:

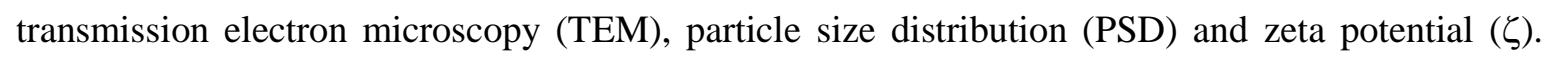
For the TEM analysis, MSPs were dispersed in dichloromethane and sonicated for 2 min to preclude aggregates. The suspension was deposited onto copper grids coated with carbon film (Aname SL, Madrid, Spain). Imaging of the MSPs samples was done using a JEOL JEM-1010 (JEOL Europe SAS, France), operating at an acceleration voltage of $80 \mathrm{kV}$. Single particle size was estimated by averaging the measured size values of 50 particles. Microscopy studies were completed by determining the size distribution of the solids dispersed in Tryptic Soy Broth (TSB) by Dynamic Light Scattering (DLS). The measurements were conducted at $25{ }^{\circ} \mathrm{C}$ using a Malvern Zetasizer Nano ZS instrument (Malvern Instruments, UK). All measurements were performed in triplicate on previously sonicated highly dilute dispersions. The zeta potential of the different solids dispersed in TSB was measured in Zetasizer Nano ZS equipment (Malvern Instruments, UK). Samples were prepared at a concentration of $1 \mathrm{mg} \mathrm{mL}^{-1}$ and the measurement was taken at $20^{\circ} \mathrm{C}$. Before taking each measurement, samples were sonicated for 2 min to preclude aggregation. The zeta potential was calculated from the particle mobility values by applying the Smoluchowski model. The average of five recordings was reported as the zeta potential.

\subsection{Caprylic acid release studies}

The CA release studies of $\mathbf{N 1}$ were performed to evaluate the release kinetics of CA from the solid and to determine the maximum amount of CA delivered by $1 \mathrm{mg}$ of particle. In a typical experiment $10 \mathrm{mg}$ of $\mathbf{N 1}$ were placed in $10 \mathrm{~mL}$ of TSB in triplicate. The mixture was maintained under stirring at $4^{\circ} \mathrm{C}, 20^{\circ} \mathrm{C}$ or $37^{\circ} \mathrm{C}$ for $5 \mathrm{~h}$. At a given time $(0.08,0.25,0.5,0.75,1.5,2,3$ and $5 \mathrm{~h})$, the suspensions were centrifuged to remove the solid, and the $\mathrm{pH}$ of the supernatant was brought down to the $\mathrm{pH}$ below the $\mathrm{pK}_{\mathrm{a}}$ of the fatty acid $\left(\mathrm{pK}_{\mathrm{a}}=4.9\right)$. In order to extract $\mathrm{CA}, 5 \mathrm{~mL}$ of $\mathrm{n}$-hexane 
were added to the aqueous solution. After phase separation, the upper layer containing CA was removed and transferred to a fresh vial, and the extraction process was repeated 3 times. The organic phase was dried under an $\mathrm{N}_{2}$ stream and solubilised with $8 \mathrm{~mL}$ of $5 \%$ (v/v) $\mathrm{H}_{2} \mathrm{SO}_{4} / \mathrm{CH}_{3} \mathrm{OH}$. The vial containing CA was incubated at $70^{\circ} \mathrm{C}$ for $30 \mathrm{~min}$. After cooling down the vial to room temperature, the reaction was quenched by adding $2 \mathrm{~mL}$ of water. The final extraction was conducted by adding $5 \mathrm{~mL}$ of $\mathrm{n}$-hexane. The upper layer containing the CA methyl ester derivative was removed to a new vial for analysis.

\subsection{Caprylic acid determination}

CA concentration was determined by GC-MS according to the method described by Han et al. (2011), but with some modifications. GC-MS was done in a gas chromatography instrument (mod. 6890N, Agilent Technologies Ltd., CA, USA) with an autoinjector (mod. 7683B) coupled to a quadruple mass detector (mod. 5975). Gas chromatographic separation was carried out by injecting $1 \mu \mathrm{L}$ of the samples into a HP-5ms capillary column $(30 \mathrm{~m} \times 0.25 \mathrm{~mm} \times 0.25 \mu \mathrm{m}$, Agilent $\mathrm{J} \& \mathrm{~W})$ in the splitless mode. Helium carrier gas was set at a constant flow rate of $1.0 \mathrm{~mL} \mathrm{~min}{ }^{-1}$. The optimised temperature programme was as follows: column temperature was held at $90^{\circ} \mathrm{C}$ for $1 \mathrm{~min}$; temperature rose from $90^{\circ} \mathrm{C}$ to $219^{\circ} \mathrm{C}$ at $15^{\circ} \mathrm{C} \mathrm{min}^{-1}$, and was held at $219^{\circ} \mathrm{C}$ for $2 \mathrm{~min}$. Then the temperature rose from $219^{\circ} \mathrm{C}$ to $290^{\circ} \mathrm{C}$ at $25^{\circ} \mathrm{C} \min ^{-1}$ and was held for $5 \mathrm{~min}$. The injection temperature was maintained at $280^{\circ} \mathrm{C}$. The ion source temperature was $200^{\circ} \mathrm{C}$, and the full scan mode was used within the $50-400 \mathrm{~m} \mathrm{z}^{-1}$ range at $0.4 \mathrm{~s} / \mathrm{scan}$ velocity.

\subsection{Microbiological analysis}

\subsubsection{Culture media}

Plate Count agar and TSB were used to grow bacteria and to prepare inoculums. Selective media were used for each studied microorganism to detect contamination during the study. Tryptone Bile x-glucuronide agar, Brilliant Green agar, Baird Parker agar base supplemented with sterile egg yolk tellurite emulsion, and Palcam agar base supplemented with polymyxin B, acriflavine and 
ceftazidime, were used to grow E. coli, S. enterica, S. aureus and L. monocytogenes, respectively. All the media were provided by Scharlau (Barcelona, Spain).

\subsubsection{Bacterial culture}

The E. coli (CECT 1103), S. enterica (CECT 915), S. aureus (CECT 240) and L. monocytogenes (CECT 936) strains were obtained from the Colección Española de Cultivos Tipo (CECT) in Valencia (Spain). Bacterial stocks were stored at $4^{\circ} \mathrm{C}$ in a solid medium before use. Bacteria cells were grown aerobically in TSB at $37^{\circ} \mathrm{C}$ for $24 \mathrm{~h}$.

\subsubsection{Antimicrobial susceptibility assays of CA}

The antimicrobial susceptibility of CA was studied using the macrodilution method of the Clinical and Laboratory Standards Institute (CLSI, 2007), but with some modifications. A wide range of concentrations of between 5 and $100 \mathrm{mM}$ of CA, dispersed in nutrient broth, was tested according to previous references of FFA inhibitory activity (Bergsson et al.,2001; Nair et al., 2004; Vasudevan et al., 2005; Nobmann et al., 2009; Chang et al., 2010). To achieve final concentrations in test tubes, different volumes of CA (between 8 and $158 \mu \mathrm{L}$ ) were added to $10 \mathrm{~mL}$ of TSB. Test tubes were inoculated with $10 \mu \mathrm{L}$ of inoculum (Section 2.7.2) and incubated with orbital stirring $(150 \mathrm{rpm})$ at $37^{\circ} \mathrm{C}$ for $48 \mathrm{~h}$. All the treatments were done in triplicate.

Bactericidal activity was quantified by preparing serial dilutions of the incubation mixtures and plating them on selective agar at $24 \mathrm{~h}$ and $48 \mathrm{~h}$ of incubation. Plates were incubated at $37^{\circ} \mathrm{C}$ for 24 h (gram-negative) and $48 \mathrm{~h}$ (gram-positive microorganisms), and the colony forming units per millilitre (CFUs $\mathrm{mL}^{-1}$ ) were determined. These values were logarithmically transformed and expressed as $\log \mathrm{CFU} \mathrm{mL} \mathrm{m}^{-1}$. Control positive values were used to quantify the growth inhibition of the diverse study conditions and to calculate the percentage of growth reduction.

\subsubsection{Effect of the MCM-41 matrix on bacterial viability}


The bacterial viability of microorganisms was tested with different concentrations of nanoparticles (N0) suspended in nutrient broth. These concentrations $\left(1,2.5,5\right.$ and $\left.10 \mathrm{mg} \mathrm{mL}^{-1}\right)$ fell within the range of the amount of loaded solid required to perform the antimicrobial susceptibility assays. To achieve the final particle concentrations, $0.04,0.1,0.2$ and $0.4 \mathrm{~mL}$ of $250 \mathrm{mg} \mathrm{mL}^{-1}$ of particle stock suspension were added to $10 \mathrm{~mL}$ of TSB in test tubes. They were inoculated with $10 \mu \mathrm{L}$ of inoculum (Section 2.7.2) and incubated with orbital stirring (150 rpm) at $37^{\circ} \mathrm{C}$ for $24 \mathrm{~h}$. All the treatments were done in triplicate. To determine bacterial viability, CFUs were counted by plating serial dilutions of bacterial suspensions on selective agar, followed by incubation at $37^{\circ} \mathrm{C}$ for $24-48$ $\mathrm{h}$ according to the studied microorganism.

\subsubsection{Antimicrobial susceptibility assays of the CA-loaded N1}

The antimicrobial activity of the CA-loaded nanoparticles $\mathbf{N 1}$ was tested using the CA concentrations of $15,18.5,20,22.5$ and $25 \mathrm{mM}$, established according to the preliminary test results (Section 2.7.3). The required amount of solids was calculated from the CA concentration actually released, determined by GC-MS (Section 2.5 and 2.6) and the different concentrations of nanoparticles tested were $1.65,2.04,2.20,2.48$ and $2.75 \mathrm{mg} \mathrm{mL}^{-1}$ TSB. Test tubes were inoculated with $10 \mu \mathrm{L}$ of inoculum (Section 2.7.2) and were incubated under orbital stirring (150 rpm) at $37^{\circ} \mathrm{C}$ for $48 \mathrm{~h}$. All the treatments were done in triplicate. To quantify bactericidal activity, serial dilutions of the incubation mixtures were plated on selective agar at $24 \mathrm{~h}$ and $48 \mathrm{~h}$ of incubation, followed by the appropriate incubation conditions explained above. CFUs were calculated, logarithmically

transformed and expressed as $\log \mathrm{CFU} \mathrm{mL}^{-1}$. Control positive values were used to quantify the percentage of growth reduction for the different test conditions.

In all the microbiological assays, a positive control (test tube containing inoculum and nutrient broth with neither CA nor MSPs) and a negative control (test tube containing CA or MSPs and nutrient broth without bacteria) were included. The positive control indicated the bacterial growth profile in the absence of an antimicrobial compound, while the negative control confirmed the absence of contamination of MSPs. 


\subsection{Detection of morphological changes in bacteria cells}

To study the morphological changes in L. monocytogenes cells caused by N1, TEM was employed in this study. The TEM specimens were prepared by the following procedure: the cells treated by unloaded particles (NO) and CA-loaded nanoparticles (N1) were collected at the end of treatment by vacuum filtration $(0.45 \mu \mathrm{m})$ performed under sterile conditions. Pellets were collected and fixed with $25 \mathrm{~g} \mathrm{~L}^{-1}$ glutaraldehyde solution for $24 \mathrm{~h}$ at $4^{\circ} \mathrm{C}$ and post-fixed with $20 \mathrm{~g} \mathrm{~L}^{-1}$ osmium tetroxide solution for $1.5 \mathrm{~h}$. Cells were centrifuged and the pellet was collected after each step of the process. After the above process ended, cells were stabilised by mixing them with a low gelling temperature agarose solution $(3 \%, \mathrm{p} / \mathrm{v})$ at $30^{\circ} \mathrm{C}$, which facilitates fixation and embedding prior to TEM observations (Ortuño et al., 2014). Next the cells inserted into solidified agar were cut into cubes (1 $\mathrm{mm}^{3}$ ). These cubes were fixed with $25 \mathrm{~g} \mathrm{~L}^{-1}$ glutaldehyde solution, post-fixed with $20 \mathrm{~g} \mathrm{~L}^{-1}$ osmium tetroxidesolution, dehydrated with $30 \mathrm{~g} \mathrm{~L}^{-1}, 50 \mathrm{~g} \mathrm{~L}^{-1}, 70 \mathrm{~g} \mathrm{~L}^{-1}$ ethanol and $100 \mathrm{~g} \mathrm{~L}^{-1}$, contrasted with uranyl acetate solution $\left(20 \mathrm{~g} \mathrm{~L}^{-1}\right)$ and embedded in epoxy resin (Durcupan, SigmaAldrich, St. Louis, MO, USA). The obtained blocks were cut using a Reichter-Jung ULTRACUT ultramicrotome (Leica Mycrosystems, Wetzlar, Germany). The obtained ultrathin sections $(0.1 \mu \mathrm{m})$ were collected in copper grids and stained with $20 \mathrm{~g} \mathrm{~L}^{-1}$ acetate uranile and $40 \mathrm{~g} \mathrm{~L}^{-1}$ lead citrate to be observed under a Philips EM 400 Transmission Electronic Microscope (Eindhoven, Holland) at $80 \mathrm{kV}$.

\subsection{Data analysis}

Statistical data processing was performed with Statgraphics Centurion XVI (Statpoint Technologies, Inc., Warrenton, VA, USA). An analysis of variance (One-way ANOVA) was done to evaluate the effect of the CA concentration and exposure time on the reduction of the growth of the studied microorganisms. The LSD (least significant difference) procedure was utilised to test for differences between averages at the $5 \%$ significance level. 


\section{Results and discussion}

\subsection{Inhibitory activity of free caprylic acid}

The antimicrobial activity of free CA was tested to establish the minimum bactericidal concentration (MBC) - the lowest concentration of a compound that gives rise to a reduction of $99.9 \%$ of the initial bacterial inoculum - of CA in a nutrient broth against different microorganisms. Figure 1 shows the growth reduction $(\%)$ of the tested microorganisms in the presence of free CA concentrations between 5 and $100 \mathrm{mM}$ after the 24-hour incubation. The study was maintained to $48 \mathrm{~h}$ of incubation and no significant differences in the growth inhibition results were found (data not shown). As seen in Figure 1A, E. coli growth was completely inhibited by free CA at a concentration that was equal to or higher than $20 \mathrm{mM}$. At non-bactericidal concentrations, reduced microorganism growth was observed in $23.012 \pm 0.004 \%$ and $34.786 \pm 0.006 \%$ for $18.5 \mathrm{mM}$ and $15 \mathrm{mM}$, respectively. Microbial growth was not affected by the $12 \mathrm{mM}$ and $5 \mathrm{mM}$ concentrations. It was thus established that the MBC fell within the 18.5-20 $\mathrm{mM}$ range for this microorganism. 

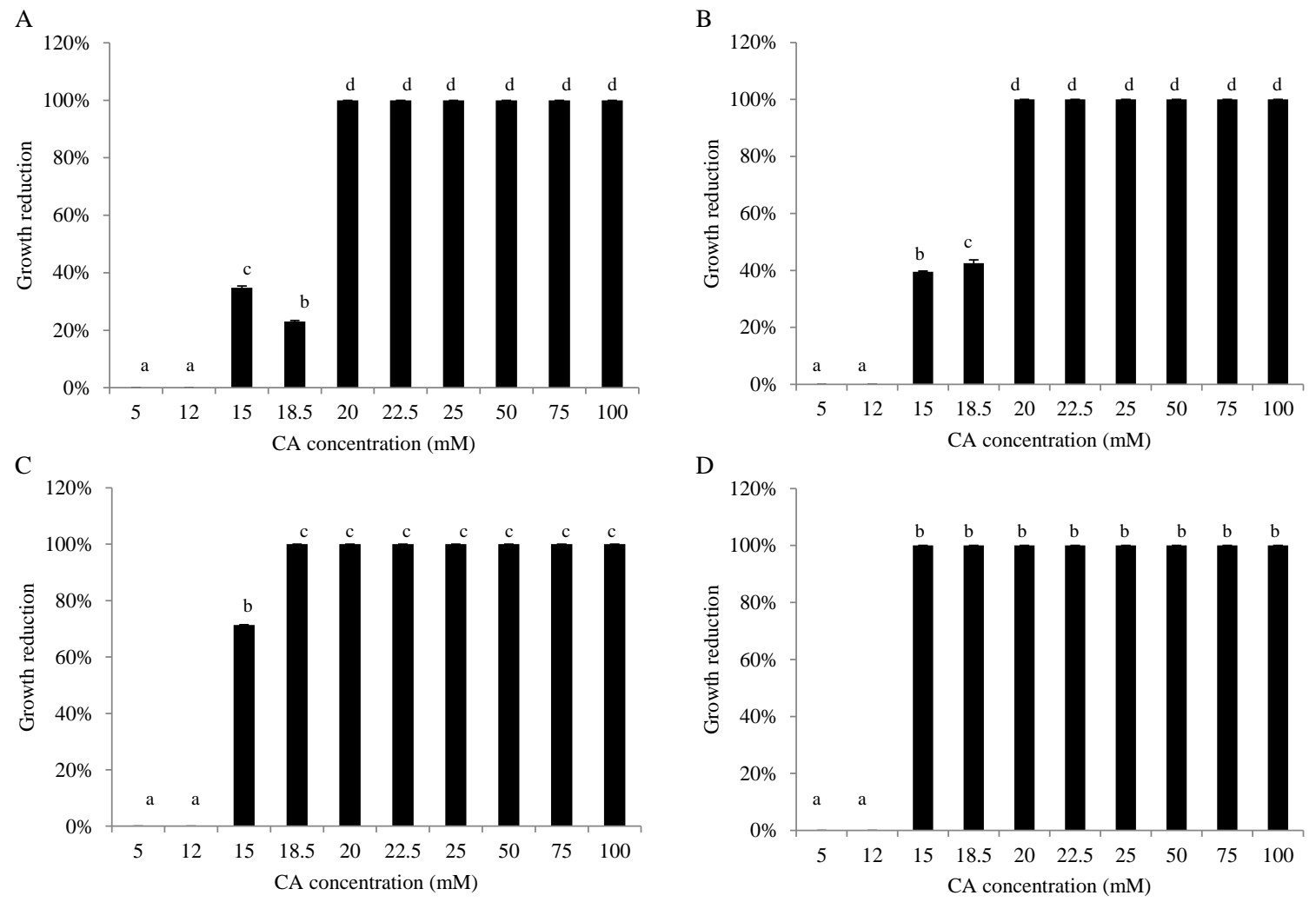

Figure 1. Reduction of microbial growth (\%) of E. coli (A), S. enterica (B), S. aureus (C) and $L$. monocytogenes (D) with free $\mathrm{CA}$ at $24 \mathrm{~h}$ of treatment. The same letters in the bars indicate homogeneous group membership ( $\mathrm{p}<0.05$ ). (Means and standard deviations, $\mathrm{n}=3$ ).

The established MBC for E. coli, in the presence of CA, in this study was lower than the values described by other authors. Nair et al. (2004) found that a $25 \mathrm{mM} \mathrm{CA}$ concentration led to a reduction of 2 logarithmic cycles of E.coli $\mathrm{O} 157: \mathrm{H} 7$ growth after incubation at $37^{\circ} \mathrm{C}$ for $24 \mathrm{~h}$, and total inhibition was achieved with a combination of low temperatures $\left(4^{\circ} \mathrm{C}\right.$ and $\left.8^{\circ} \mathrm{C}\right)$ and $\mathrm{CA} 50$ $\mathrm{mM}$ in a study of microbial inhibition in milk. Another study was performed with alfalfa seeds (Chang et al., 2010), in which a more marked reduction in E. coli was reported using an FFA concentration of $25 \mathrm{mM}$ in 0.75 logarithmic cycles after $12 \mathrm{~h}$ of treatment.

The differences between our results and those reported by other authors might be due to the chosen bacterial strain, studied temperature and matrix effect. In food, the presence of certain molecules such as proteins can produce the formation of complexes with $\mathrm{CA}$, which hampers $\mathrm{CA}$ in 
performing its antimicrobial activity (Kabara et al., 1972). In such cases, higher antimicrobial doses are required to achieve the same effect on microbial growth.

CA affected $S$. enterica growth, with MBC falling within the same range as in the E. coli assays (18.5-20 mM), as shown in Figure 1B. These MBC values are lower than other previously reported. In the study of Chang et al. (2010), Salmonella spp. populations on alfalfa seeds reduced to below 0.6 logarithmic cycles within $6 \mathrm{~h}$ of exposure to CA $75 \mathrm{mM}$, and maximum Salmonella spp. reductions of 1.28 and 2.3 logarithmic cycles were achieved at the $25 \mathrm{mM}$ and the $50 \mathrm{mM} \mathrm{CA}$ concentration, respectively. However, Choi et al. (2013) studied the antimicrobial activity of CA and other compounds against $S$. enterica serovar Typhimurium in reconstituted infant formula, and established that the microorganism was inactivated in the presence of $\mathrm{CA} 40 \mathrm{mM}$ at $40{ }^{\circ} \mathrm{C}$ for 10 min. The differences between these results may be due to the above-mentioned effect of different variables. However, the study of Vasudevan et al. (2005), performed in a nutrient medium, found that the $50 \mathrm{mM}$ CA concentration reduced Salmonella Enteritidis by approximately $5 \log \mathrm{CFU} \mathrm{mL}^{-}$ ${ }^{1}$ after a 1-minute incubation and showed complete pathogen inactivation at $24 \mathrm{~h}$.

As seen in Figure 1C, the inhibition of $S$. aureus growth was greater than that of gram-negative bacteria. Different concentrations can be divided into three groups to show complete inhibition (18.5-100 mM), partial inhibition $(15 \mathrm{mM})$ or no reduction $(5-12 \mathrm{mM})$. The $\mathrm{MBC}$ of CA was lower than for E. coli and S. enterica, and fell within the 15-18.5 mM range. These results are similar to those obtained in the study of Bergsson et al. (2001), who used culture broth. In this study, the CA $10 \mathrm{mM}$ concentration gave rise to a slightly inhibitory effect on $S$. aureus after a 10-minute incubation at $37^{\circ} \mathrm{C}$.

L. monocytogenes was the microorganism that was most affected by free CA (Fig. 1D). Complete inhibition of bacteria occurred at concentrations between $15-100 \mathrm{mM}$, so the $\mathrm{MBC}$ would be between $12.5 \mathrm{mM}$ and $15 \mathrm{mM}$. These results agree with the study of Nobmann et al. (2009), which established a minimum inhibitory concentration of $5 \mathrm{mM}$ for Listeria innocua and of $\geq 5 \mathrm{mM}$ for different L. monocytogenes strains after incubation for $18 \mathrm{~h}$ in nutrient broth at $35^{\circ} \mathrm{C}$. A study of 
antimicrobial susceptibility of CA in milk (Nair et al., 2004) reported only a reduction of 3 logarithmic cycles after a 24 -hour incubation at $37^{\circ} \mathrm{C}$ using the CA $25 \mathrm{mM}$ concentration.

Free CA proved more effective against gram-positive microorganisms as it reduced $L$. monocytogenes growth to below the limit of detection for a concentration of between $15 \mathrm{mM}$ and $100 \mathrm{mM}(\mathrm{MBC}<15 \mathrm{mM})$, and obtained an MBC within the $15-18.5 \mathrm{mM}$ range for $S$. aureus. The MBC for the tested gram-negative bacteria fell within a slightly higher range, with values between $18.5 \mathrm{mM}$ and $20 \mathrm{mM}$. These results coincide with those of other studies, which showed that the antimicrobial activity of CA was greater against gram-positive bacteria (Nieman, 1954; Thormar et al., 1987; Nobmann et al., 2009) than against gram-negative microorganisms. These differences in microbial susceptibility can be attributed to differences in the structure and permeability of the bacterial cell membrane between gram-positive (thick layer of peptidoglycan) and gram-negative microorganisms (thick layer of peptidoglycan and outer membrane with lipopolysaccharides) (Nair et al., 2004; Hajipour et al., 2012).

The MBCs obtained for each microorganism were used to establish the range of concentrations in the study conducted with the CA-loaded MSPs.

\subsection{Synthesis and characterisation of the CA-loaded mesoporous support}

In a first step of the work, the starting MCM-41 support was synthesised following well-known procedures using n-ctyltrimetylammonium $(\mathrm{CTAB})$ as a structure director agent and tetraethylorthosilicate (TEOS) as a silica source. After removal the surfactant by calcination the starting MCM-41 support was obtained (N0). Then, the pores of the MCM-41 support were loaded with CA (N1).

\subsubsection{Characterisation of mesoporous silica particles}

Solids N0 and N1 were characterized by standard techniques. The mesoporous structure of N0 after calcination was clearly confirmed by TEM (see Figure 2). From these studies is as also observed that the size and morphology of the CA-loaded N1 nanoparticles was very similar to that found for 
N0 indicating that the loading process did not affected to the characteristics of the mesoporous support. Figure 2 also shows the typical mesoporosity of the nanoparticles as alternate black and white stripes.
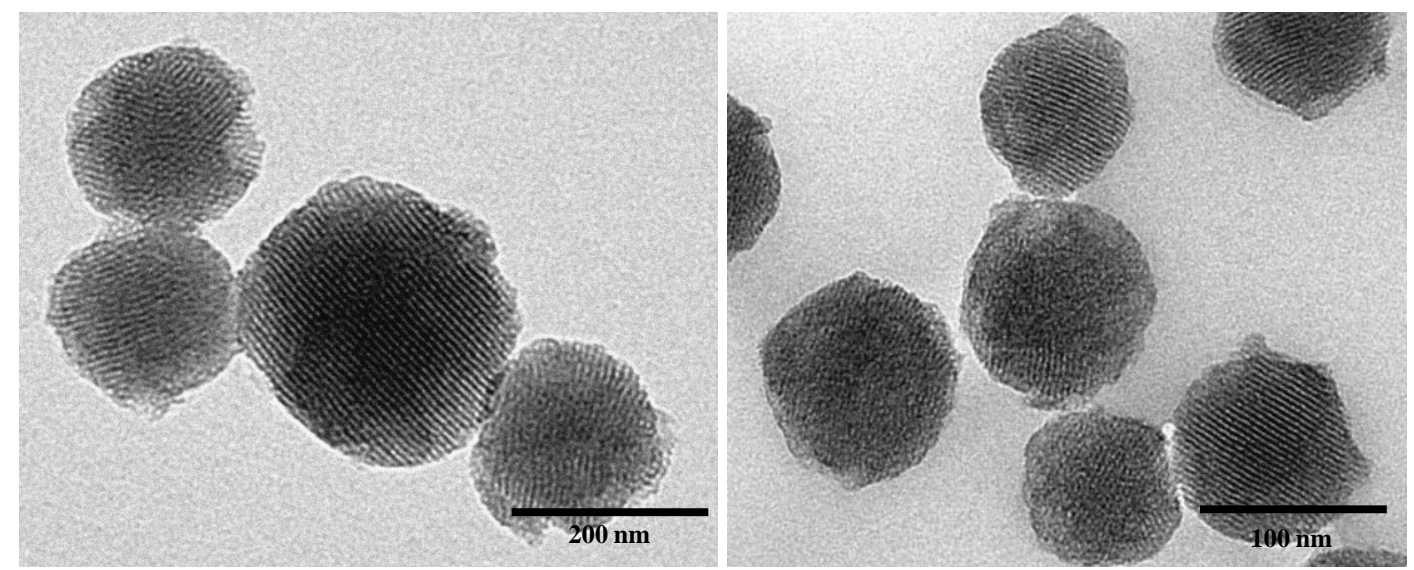

Figure 2. TEM images of inorganic MCM-41 nanoparticle calcined matrix No.

Besides porosity, the morphologic analysis with TEM allowed to calculate the size of nanoparticles (see Table 1). Moreover particles size was also determined by light diffraction studies (Table 1). In addition, Table 1 also displays the zeta potential determined for the $\mathbf{N} \mathbf{0}$ and $\mathbf{N 1}$ nanoparticles.

Table 1. Particle size of the different MCM-41 particles determined by TEM (dry) or Light Diffraction (dispersed in TSB), and the zeta potential (Means and standard deviations).

\begin{tabular}{lccc}
\hline & \multicolumn{2}{c}{ Particle size $(\mu \mathrm{m})$} & \\
\cline { 2 - 3 } Particle & TEM & $\mathrm{d}(0.5)$ & Zeta potential $(\mathrm{mV})$ \\
\hline N0 & $0.088 \pm 0.013$ & $1.580 \pm 0.001$ & $-17.05 \pm 2.30$ \\
N1 & $0.114 \pm 0.0183$ & $1.634 \pm 0.001$ & $-14.68 \pm 0.92$ \\
\hline
\end{tabular}

As Table 1 shows nanoparticles N0 and N1 exhibited sizes that fell within the range of ca. $100 \mathrm{~nm}$, according to the TEM analysis. In contrast, when light scattering was used, size values of ca. 160 
nm were found. This difference must be related with the different media used in both techniques; i.e. vacuum in TEM versus TSB for light scattering. This result suggested that there was some interaction between the nanoparticles and the TBS medium that resulted in a size increment. This interaction may be explained if taking into account that the nanoparticles are negatively charged (see zeta potential values in Table 1) and that interaction with positively charged species in the TBS medium are highly probable. This is in agreement with studies of García-Saucedo et al. (2011). Interaction effects depend on the isoelectric point of particles, the charge and molecular structure of the organic compound, and the $\mathrm{pH}$ of dispersions.

\subsubsection{Characterisation of CA release}

CA release kinetics were performed at $4^{\circ} \mathrm{C}, 20^{\circ} \mathrm{C}$ and $37^{\circ} \mathrm{C}$ to check the effect of temperature on the release behaviour of CA from N1. The release profile of CA from N1 in a nutrient broth suspension at $37^{\circ} \mathrm{C}$ is shown in Figure 3. Progressive controlled delivery was produced during the first assay hours. The maximum release was achieved after $3 \mathrm{~h}$. Moreover from the release studies we calculated that $\mathrm{N} 1$ nanoparticles suspended in TSB are able to release $9.08 \pm 0.24 \mathrm{mmol} \mathrm{CA} \mathrm{g}^{-1}$ solid. This value was used later (vide infra) to calculate the required quantity of CA-loaded MSP (N1 solid) to be dispersed in the nutrient broth to achieve the objective concentrations for the antimicrobial susceptibility assays described in Section 2.7.5. Results of release studies carried out at refrigeration $\left(4^{\circ} \mathrm{C}\right)$ and room temperature $\left(20^{\circ} \mathrm{C}\right)$ showed that content of $\mathrm{CA}$ released at refrigeration or room temperature was ca. $30 \%$ lower than $\mathrm{CA}$ released at $37^{\circ} \mathrm{C}$, meaning that temperature affects the release kinetics of the fatty acid. However, at these temperatures, the growth of the tested bacteria is limited. In general, the growth rate of the studied microorganisms is between $5^{\circ} \mathrm{C}$ and $40^{\circ} \mathrm{C}$ and that the growth rate is double for each $10^{\circ} \mathrm{C}$ increase (McKinney, 2004). Thus, the antimicrobial activity of CA-loaded $\mathrm{N} 1$ nanoparticles was checked at $37^{\circ} \mathrm{C}$ in order to evaluate the effect of encapsulated CA on bacterial viability in the optimal growth conditions (see section 3.4). 


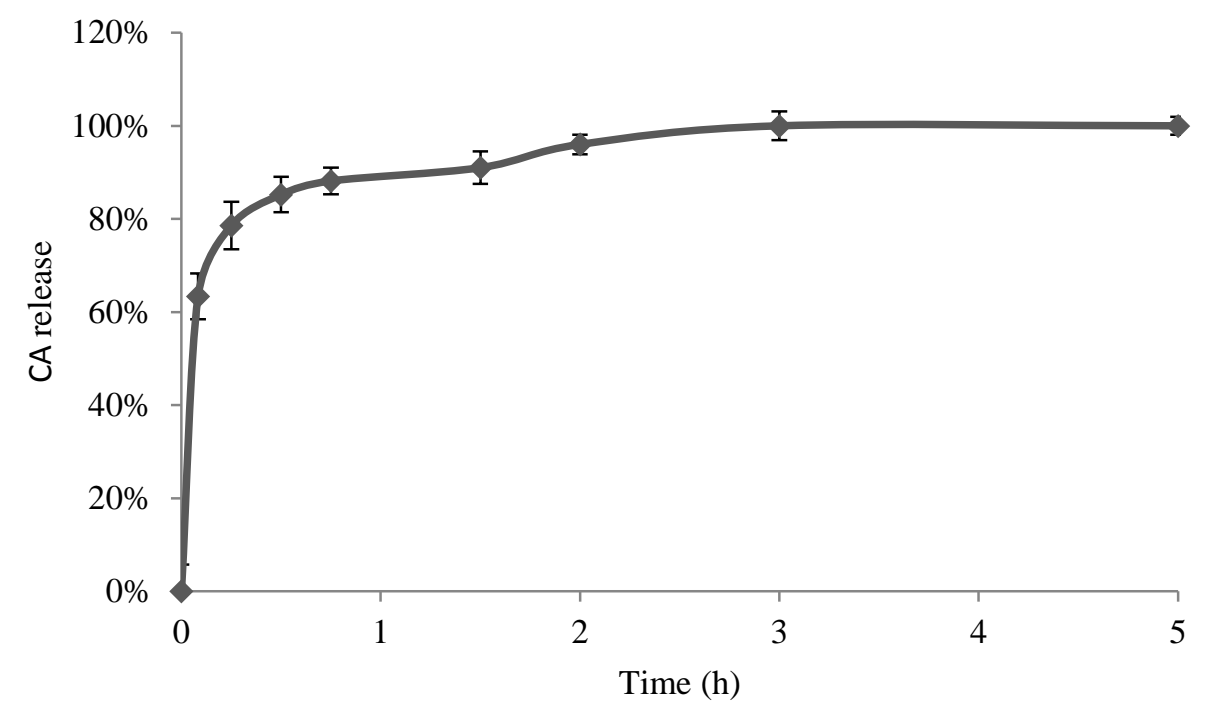

Figure 3. Release profile of CA from N1 solid in a TSB (Means and standard deviations, $n=3$ ).

\subsection{Effect of the mesoporous silica matrix on bacterial viability}

To test the effect of the mesoporous silica matrix on bacteria, the bacterial viability of the microorganisms was tested with nanoparticles (NO) at concentrations of 1-10 $\mathrm{mg} \mathrm{mL}^{-1}$ suspended in nutrient broth. In all cases, the $100 \%$ survival of microorganisms, compared with the positive controls, indicated that the treatment with unloaded particles did not affect the microbial growth of any bacteria. These results are in accordance with the data obtained in the study performed by Wehling et al. (2013), which investigated the effect of silica particles on bacterial viability, whose size was between 15 and $500 \mathrm{~nm}$. These authors established that particles displayed no inhibitory properties independently of their particle size. Besides bacterial viability assays, TEM images of the bacteria treated with N0 were obtained (see Section 3.5). In these images, the treated bacteria did not show irreversible cell damaging, which means that the unloaded solid (NO) is innocuous itself under the tested conditions.

\subsection{Antimicrobial activity of CA-loaded N1 nanoparticles}

According to the results obtained in Section 3.1, the range of concentrations in the antimicrobial assays of the CA-loaded N1 was established to be $15-25 \mathrm{mM}$. The inhibitory effect of the CA- 
loaded N1 nanoparticles against E. coli, S. enterica, S. aureus and L. monocytogenes at $24 \mathrm{~h}$ and 48 $\mathrm{h}$ of incubation at $37^{\circ} \mathrm{C}$ is shown in Figure 4.

As Figure 4A illustrates, E. coli growth was affected by $\mathbf{N 1}$ solids at concentrations of between 20 $\mathrm{mM}$ and $25 \mathrm{mM}$, and total inhibition was accomplished. The non-bactericidal concentrations, 15 $\mathrm{mM}$ and $18.5 \mathrm{mM}$, were divided into two statistically different groups where the higher the concentration, the lower the growth of the microorganism. Thus the MBC of the N1 particles fell within the $18.5-20 \mathrm{mM}$ range for this microorganism.

The loaded nanoparticles displayed a completely different behaviour with $S$. enterica (Fig. 4B) if compared with other studied bacteria. None of the concentrations of the N1 solids was bactericidal to $S$. enterica $24 \mathrm{~h}$ after incubation. In this case reductions of $59.81 \pm 0.03 \%$ and $57.13 \pm 0.05 \%$ were obtained at a concentration of $25 \mathrm{mM}$ and $22.5 \mathrm{mM}$, respectively. At $48 \mathrm{~h}$ (grey bars), four statistically different groups of the concentration levels reached an MBC within the 20-22.5 mM range. These results indicate that the inhibitory effect of $\mathbf{N} 1$ was slower for S. enterica than for the rest of microorganisms. Since free CA had a similar effect on S. enterica than on E. coli, it can be stated that both gram-negative bacteria have similar sensitivity to the bactericidal action of CA. Thus, the differences in the action of $\mathbf{N 1}$ against this bacterium could only be related to different release kinetics of CA when S. enterica is in the media. Some previous workers have recently demonstrated that Salmonella spp. exhibits higher attachment and adhesion strength on surfaces than other similar strains such as E. coli (Abban, Jakobsen \& Jespersen, 2012; Zhang et al., 2014). This adhesion tendency could create aggregates among the aggregative fimbriae of the cells responsible of the bacterial attachment- and the nanoparticles. The aggregates formed between the bacteria and the nanoparticles could hamper the release of the fatty acid, and as a consequence, to slow the microbial action of CA.

The counts of S. aureus (Fig. 4C) were completely inhibited by the loaded nanoparticles at the 22.5 $\mathrm{mM}$ and $25 \mathrm{mM}$ concentrations and were slightly affected by the $15 \mathrm{mM}$ and $18.5 \mathrm{mM}$ concentrations. A MBC of 20-22.5 mM was calculated in this case. Significant differences were 
observed for treatment time levels at the $20 \mathrm{mM}$ concentration, which resulted in an increased $\mathrm{MBC}$ within the $18.5-20 \mathrm{mM}$ range at the $48 \mathrm{~h}$ incubation time.

The bactericidal effect of $\mathbf{N 1}$ solids for L. monocytogenes (Fig. 4D) was 18.5-20 mM at different treatment times, and this result fell within the same range as the E. coli and S. aureus assays. Otherwise, lower concentrations further reduced microbial growth at the incubation time of $24 \mathrm{~h}$ than at $48 \mathrm{~h}$, and statistically differences were shown for this factor at the $18.5 \mathrm{mM}$ concentration.

A

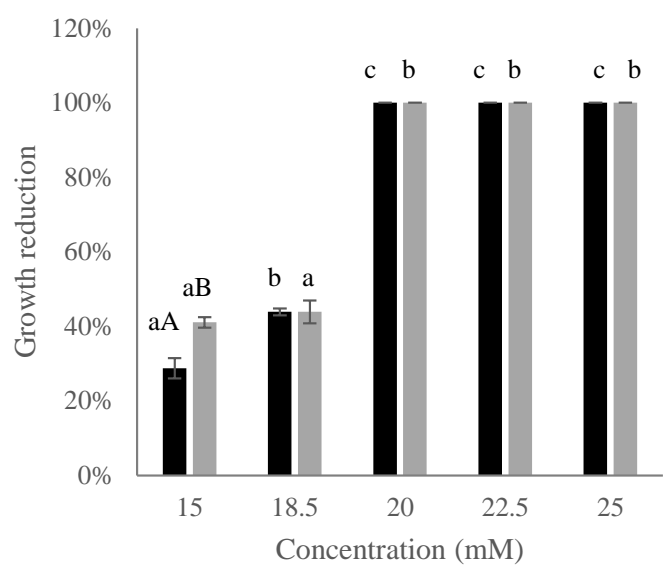

$\mathrm{C}$

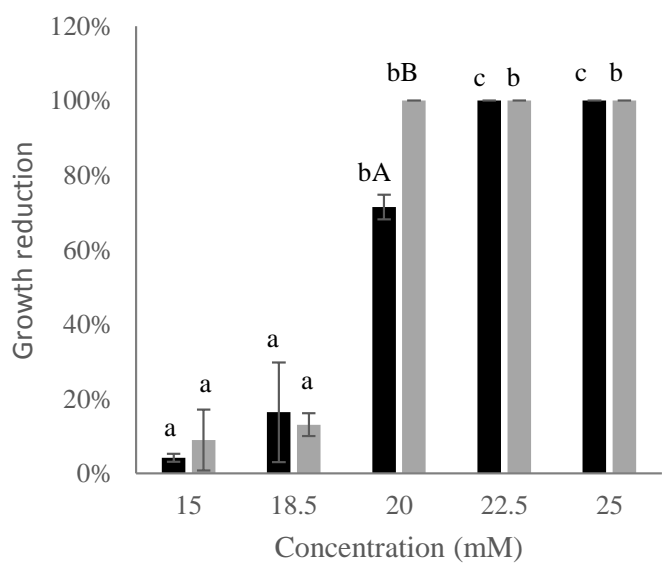

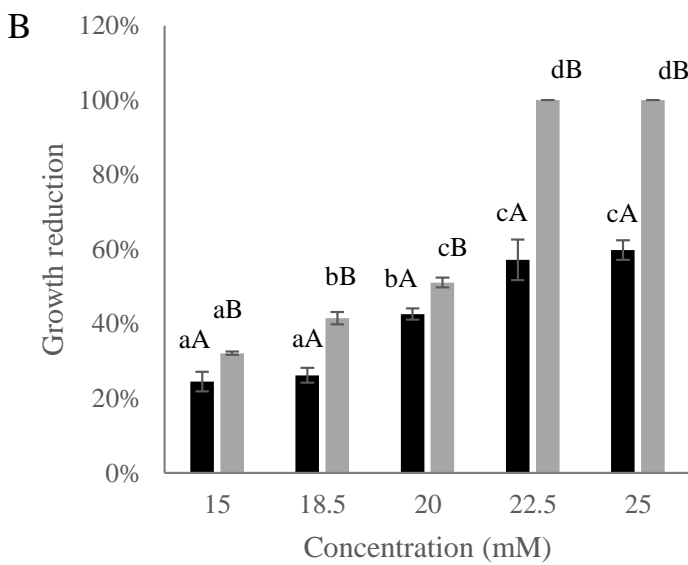

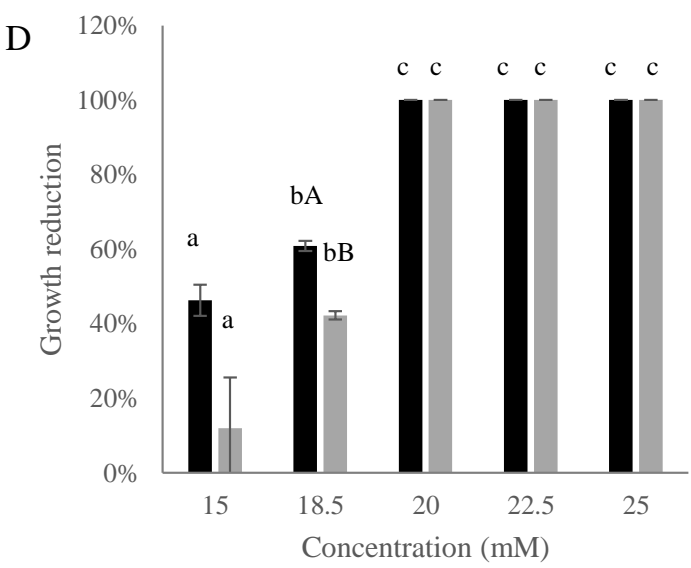

Figure 4. Reduction of microbial growth (\%) of E. coli (A), S. enterica (B), S. aureus (C) and $L$. monocytogenes (D) with N1 solids at $24 \mathrm{~h}$ (black) and $48 \mathrm{~h}$ (grey) of treatment. Different letters in the bars indicate statistically significant differences $(\mathrm{p}<0.05)$ from levels of concentration (small letters) and exposure time (capital letters) (Means and standard deviations, $\mathrm{n}=3$ ). 
When comparing the effect of free CA and CA-loaded nanoparticles, it was stated that the antibacterial activity of the free and entrapped CA against $E$. coli growth fell within the same range (18.5-20 mM) for both conditions. However, free fatty acid more effectively reduced the population for S. enterica, S. aureus and L. monocytogenes. Despite the slight variances of antibacterial activity for free CA and CA-loaded nanoparticles, that may be related with particular differences in CA delivery from $\mathbf{N 1}$ in the presence of the different bacteria, the results indicated that mesoporous silica nanoparticles are suitable reservoirs for CA encapsulation and control delivery for bactericidal applications.

Thus, the proposed system was able to maintain the antimicrobial activity despite the encapsulation. This property allows the incorporation of CA-loaded nanoparticles into matrixes were the final flavour or taste is important (Hulankova et al., 2013) or into matrixes where CA could interact with food constituents dismissing its antimicrobial activity (Kabara et al., 1972). Moreover, the obtained results open the possibility to create gated mesoporous silica particles loaded with CA to be used in on-command delivery applications. The presence of silanol groups on the surface of the MSPs offers the possibility of functionalise their surface with organic molecules, generally called molecular gates, able to block or allow the release of the cargo under the presence of target stimuli. This molecular gates have been proposed by different authors to develop carriers for smart stimuli-responsive delivery in the gastrointestinal tract with response to biological stimuli such as pH or enzymes including amylases, proteases or gut microflora enzymes (Mas et al., 2013; Popat et al., 2014; Pérez-Esteve et al., 2015).

\subsection{Morphological changes in Listeria monocytogenes treated with unloaded (NO) and CA-loaded}

\section{(N1) nanoparticles}

Figure 5 depicts the TEM images of the typical rod-shaped morphology of untreated $L$. monocytogenes cells, showing the intracellular organisation with a complete cytoplasm and inner material surrounded by an intact cell membrane and cell wall (Fig. 5A-B). The bacteria cells grown in the presence of unloaded nanoparticles (N0) are seen in Figure 5C and D. In this case the cell 
wall and cell membrane appeared to be complete, but slightly modified, as the cytoplasm content inside cells showed empty regions. These cavities might be due to the aggregation or precipitation of internal cell components, or to the removal of part of the cytoplasmic content, which were seen outside the bacteria (Fig. 5D). Despite these changes, bacterial viability was not affected by the presence of nanoparticles at any of the tested concentrations (see Section 3.3) suggesting that bacteria could probably be able to repair cell damage and to maintain its viability. These results are in accordance with the conclusions drawn by Wehling et al. (2013), in which silica particles of different sizes $(15,50$ and $500 \mathrm{~nm})$ had no effect on the viability of diverse bacteria strains.

The TEM images of the cells treated with CA-loaded N1 nanoparticles at the $25 \mathrm{mM}$ concentration of fatty acid are included in Figure 5E and F. N1 treatment produced severe effects on the morphology of the bacteria and disrupted the cell envelope integrity, along with leakage of cellular contents. These observations are clearly in agreement with cell viability reduction described above. 

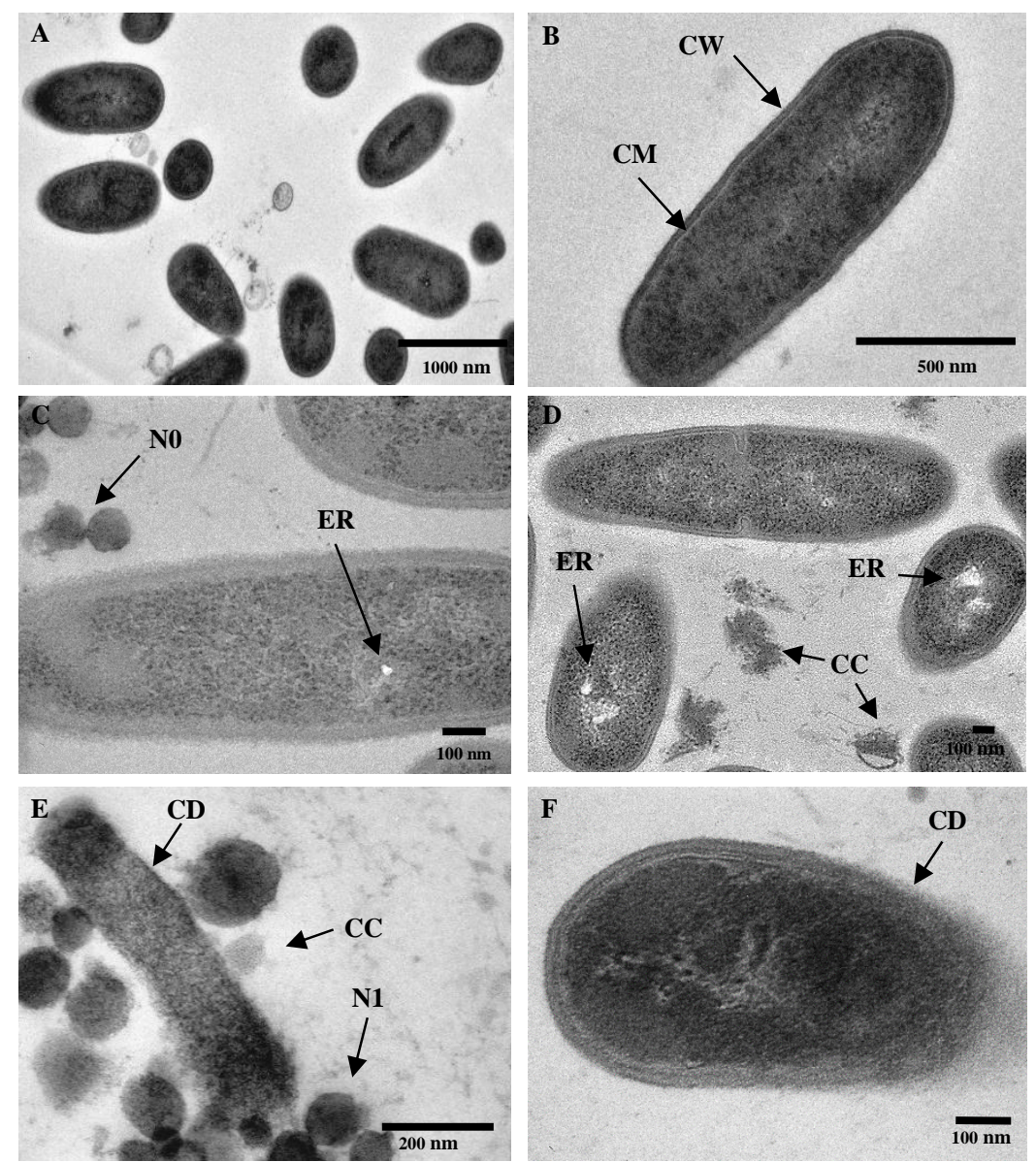

Figure 5. TEM micrographs by ultrathin sectioning of L. monocytogenes. Images A-B show untreated cells; images C-D show cells in the presence of nanoparticles N0; images E-F show cells treated with CA-loaded nanoparticles N1. CW: cell wall; CM: cell membrane; ER: empty regions; CC: cytoplasmic content; CD: cell wall and membrane damage.

According to several authors the mechanism of action of CA on bacteria cells is based on the alteration of the different essential processes occurring at the cell envelope (Bergsson et al., 2001; Chang et al., 2010; Desbois \& Smith, 2010), which results in microorganism inhibition. CA in particular, and FFAs in general, are known to create pores that may penetrate the cell membrane, this induces portions of the lipid bilayer to be released and disruption of membrane permeability takes place (Choi et al., 2013). 


\section{Conclusions}

In recent years, consumers demand natural products or new administration forms that allow the concentrations of traditional antimicrobials to lower to prevent bacterial resistance. This study has demonstrated the effectiveness of $\mathrm{CA}$ as an antimicrobial compound using a nano-encapsulated formulation based in the use of silica mesoporous supports. Free CA was more effective against gram-positive microorganisms and provided MBC values within the $12-15 \mathrm{mM}$ range. For gramnegative bacteria free $\mathrm{CA}$ gave $\mathrm{MBC}$ values between $18.5 \mathrm{mM}$ and $20 \mathrm{mM}$ depending on the bacteria. This study has also shown the suitability of MSPs to entrap CA and to maintain its antimicrobial activity. In fact CA-loaded MSPs proved to be an appropriate support for CA encapsulation with $\mathrm{MBC}$ falling within the 18.5-20 $\mathrm{mM}$ range. TEM studies confirmed the inhibitory effect to be the result of cellular damage. The obtained results confirm the potential usefulness of CA entrapped in mesoporous supports to inhibit microbial growth with some added advantages such as the masking of the unpleasant flavour of the fatty acid, avoiding the interaction of the active principle with food matrix, or allowing the development of smart delivery system for the release of the antimicrobial compound in the site of action after incorporation of molecular gates in the supports. We believe that nano-encapsulation of FFAs may be an appealing option the design of new bactericidal formulations that may found applications in some fields including the food industry.

\section{Acknowledgements}

Authors gratefully acknowledge the financial support from the Ministerio de Economía y Competitividad (Projects AGL2012-39597-C02-01, AGL2012-39597-C02-02 and MAT201238429-C04-01) and the Generalitat Valenciana (Project PROMETEOII/2014/047). M.R.R. and E.P.E. are grateful to the Ministerio de Ciencia e Innovación for their grants (AP2010-4369 and AP2008-0620). 


\section{References}

Abban, S., Jakobsen, M., \& Jespersen, L. (2012). Attachment behaviour of Escherichia coli K12 and Salmonella Typhimurium P6 on food contact surfaces for food transportation. Food microbiology, 31(2), 139-147.

Al Shamsi, M., Al Samri, M.T., Al-Salam, S., Conca, W., Shaban, S., Benedict, S., Tariq, S., Biradar, A.V., Penefsky, H.S., Asefa, T., Souid, A.K. (2010). Biocompatibility of calcined mesoporous silica particles with cellular bioenergetics in murine tissues. Chem. Res. Toxicol., 23, 1796-1805.

Aznar, E., Martínez-Máñez, R., Sancenón, F. (2009). Controlled release using mesoporous materials containing gate-like scaffoldings. Expert Opin. Drug Deliv., 6, 643-655

Bergsson, G., Arfinnson, J., Steingrinsson, O., Thormar, H. (2001). Killing of Gram-positive cocci by fatty acids and monoglycerides. APMIS Journal, 109, 670-678.

Bernardos, A., Mondragón, L., Aznar, E., Marcos, M.D., Martínez-Máñez, R., Sancenón, F., Soto, J., Barat, J.M., Pérez-Payá, E., Guillem, C., Amorós, P. (2010). Enzyme-responsive intracellular controlled release using nanometric silica mesoporous supports capped with 'saccharides'. ACS nano, 4(11), 6353-6368.

CLSI (2007). Performance standards for antimicrobial susceptibility testing; seventeenth informational supplement. Clinical and Laboratory Standards Institute, M100-S17, 27 (1).

Chang, S., Redondo-Solano, M., Thippareddi, H. (2010). Inactivation of Escherichia coli O157:H7 and Salmonella spp. on alfalfa seeds by caprylic acid and monocaprylin. International Journal of Food Microbiology, 144, 141-146.

Choi, M.J., Kim, S.A., Lee, N.Y., Rhee, M.S. (2013). New decontamination method based on caprylic acid in combination with citric acid or vanillin for eliminating Cronobacter sakazakii and Salmonella enterica serovar Typhimurium in reconstituted infant formula. International Journal of Food Microbiology, 166, 499-507.

Coll, C., Bernardos, A., Martínez-Máñez, R., Sancenón F. (2013). Gated silica mesoporous supports for controlled release and signaling applications. Acc. Chem. Res., 46, 339-349.

Desbois, A.P., Smith, V.J. (2010). Antibacterial free fatty acids: activities, mechanisms of action and biotechnological potential. Appl Microbiol Biotechnol., 85, 1629-1642.

EFSA (2013). The European Union Summary Report on antimicrobial resistance in zoonotic and indicator bacteria from humans, animals and food in 2011. EFSA Journal, 11(5), 3196-3359. (http://www.efsa.europa.eu/en/efsajournal/pub/3196.htm). [30/06/2014]

García-Saucedo, C., Field, J. A., Otero-Gonzalez, L., Sierra-Álvarez, R. (2011). Low toxicity of $\mathrm{HfO}_{2}, \mathrm{SiO}_{2}$, $\mathrm{Al}_{2} \mathrm{O}_{3}$ and $\mathrm{CeO}_{2}$ nanoparticles to the yeast, Saccharomyces cerevisiae. Journal of hazardous materials, 192(3), 1572-1579.

Gyawali, R., Ibrahim, S.A. (2014). Natural products as antimicrobial agents. Food Control, 46, 412-429.

Hajipour, M.J., Fromm, K.M., Ashkarran, A.A., Jimenez de Aberasturi, D., Ruiz de Larramendi, I., Rojo, T., Serpooshan, V., Parak, W.J., Mahmoudi, M. (2012). Antibacterial properties of nanoparticles. Trends in Biotechnology, 30(10), 499-511.

Han, L.D., Xia, J.F., Liang, Q.L., Wang, Y., Wang, Y.M., Hu, P., Li, P., Luo, G.A. (2011). Plasma esterified and non-esterified fatty acids metabolic profiling using gas chromatography-mass spectrometry and its application in the study of diabetic mellitus and diabetic nephropathy. Analytica Chimica Acta, 689(1), 85-91.

Hirazawa, N., Oshima, S., Hata, K. (2001a). In vitro assessment of the antiparasitic effect of caprylic acid against several fish parasites. Aquaculture, 200, 251-258.

Hirazawa, N., Oshima, S., Hara, T., Mitsuboshi, T., Hata, K. (2001b). Antiparasitic effect of medium-chain fatty acids against the ciliate Cryptocaryon irritans infestation in the red sea bream Pagrus major. Aquaculture, 198, 219-228.

Hulankova, R., Borilova, G., Steinhauserova, I. (2013). Combined antimicrobial effect of oregano essential oil and caprylic acid in minced beef. Meat Science, 95, 190-194.

Jang, H.I., Rhee, M.S. (2009). Inhibitory effect of caprylic acid and mild heat on Cronobacter spp. (Enterobacter sakazakii) in reconstituted infant formula and determination of injury by flow cytometry. International Journal of Food Microbiology, 133, 113-120.

JECFA (Joint FAO \& WHO Expert Committee on Food Additives) (2000). Evaluation of certain food additives and contaminants. World Health Organization technical report series 896, 1.

Kabara, J.J., Swieczkowski, D.M., Conley, A.J., Truant, J.P. (1972). Fatty acids and derivatives as antimicrobial agents. Antimicrob. Agents Chemother., 2(1), 23-28.

Manzano, M., Vallet-Regí, M. (2010). New developments in ordered mesoporous materials for drug delivery. J. Mater. Chem., 20, 5593-5604. 
Mas, N., Agostini, A., Mondragón, L., Bernardos, A., Sancenón, F., Marcos, M.D., Martínez-Máñez, R., Costero, A.M., Gil, S., Merino-Sanjuán, M., Amorós, P., Orzáez, M., Pérez-Payá, E. (2013). EnzymeResponsive Silica Mesoporous Supports Capped with Azopyridinium Salts for Controlled Delivery Applications. Chemistry-A European Journal, 19(4), 1346-1356.

McKinney R.E. (2004). Environmental pollution control microbiology: a fifty-year perspective. CRC Press.

Nair, M.K.M., Vasudevan, P., Hoagland, T., Venkitanarayanan, K. (2004). Inactivation of Escherichia coli O157:H7 and Listeria monocytogenes in milk by caprylic acid and monocaprylin. Food Microbiology, 21, 611-616.

Nieman, C. (1954). Influence of trace amounts of fatty acids on the growth of microorganisms. Bacteriol. Rev., 18(2), 147-163.

Nobmann, P, Smith, A., Dunne, J., Henehan, G., Bourke, P. (2009). The antimicrobial efficacy and structure activity relationship of novel carbohydrate fatty acid derivatives against Listeria spp. and food spoilage microorganisms. International Journal of Food Microbiology, 128, 440-445.

Ortuño, C., Quiles, A., Benedito, J. (2014). Inactivation kinetics and cell morphology of E. coli and $S$. cerevisiae treated with ultrasound-assisted supercritical $\mathrm{CO}_{2}$. Food Research International, 62, 955-964.

Park, S.Y., Pendleton, P. (2012). Controlled release of allyl isothiocyanate for bacteria growth management. Food control, 23, 478-484.

Park, S.Y., Barton, M., Pendleton, P. (2012). Mesoporous silica SBA-15 for natural antimicrobial delivery. Powder Technology, 223, 77-82.

Pérez-Esteve, E., Oliver, L., García, L., Nieuwland, M., de Jongh, H. H., Martínez-Máñez, R., Barat, J. M. (2014). Incorporation of Mesoporous Silica Particles in Gelatine Gels: Effect of Particle Type and Surface Modification on Physical Properties. Langmuir, 30, 6970-6979.

Pérez-Esteve, E., Fuentes, A., Coll, C., Acosta, C., Bernardos, A., Amorós, P., Marcos, M.D., Sancenón, F., Martínez-Máñez, R., Barat, J.M. (2015). Modulation of folic acid bioaccessibility by encapsulation in pHresponsive gated mesoporous silica particles. Microporous and Mesoporous Materials, 202, 124-132.

Popat, A., Jambhrunkar, S., Zhang, J., Yang, J., Zhang, H., Meka, A., Yu, C. (2014). Programmable drug release using bioresponsive mesoporous silica nanoparticles for site-specific oral drug delivery. Chemical Communications, 50(42), 5547-5550.

Skrivanová, E., Molatová, Z., Marounek, M. (2008). Effects of caprylic acid and triacylglycerols of both caprylic and capric acid in rabbits experimentally infected with enteropathogenic Escherichia coli O103. Veterinary Microbiology, 126, 372-376.

Slowing, I.I., Vivero-Escoto, J.L., Wu, C.W., Lin, V.S.Y. (2008). Mesoporous silica nanoparticles as controlled release drug delivery and gene transfection carriers. Advanced Drug Delivery Reviews, 60, 1278-1288.

Solís de los Santos, F., Hume, M., Venkitanarayanan, K., Donoghue, A.M., Hanning, I., Slavik, M.F., Aguiar, V.F., Metcalf, J.H., Reyes-Herrera, I., Blore, P.J., Donoghue, D.J. (2010). Caprylic acid reduces enteric campylobacter colonization in market-aged broiler chickens but does not appear to alter cecal microbial populations. Journal of Food Protection, 73(2), 251-257.

Sozer, N., Kokini, J.L. (2009). Nanotechnology and its applications in the food sector. Trends in biotechnology, 27(2), 82-89.

Suh, W.H., Suslick, K.S., Stucky, G.D., Suh, Y.H. (2009). Nanotechnology, nanotoxicology and neuroscience. Prog. Neurobiol., 87, 133-170.

Thormar, H., Isaacs, C.E., Brown, H.R., Barshatzky, M.R., Pessolano, T. (1987). Inactivation of enveloped viruses and killing cells by fatty acids and monoglycerides. Antimicrobial Agents and Chemoterapy, 31, 27-31.

Vasudevan, P., Marek, P., Nair, M.K.M., Annamalai, T., Darre, M., Khan, M., Venkitanarayanan, K. (2005). In Vitro Inactivation of Salmonella Enteritidis in Autoclaved Chicken Cecal Contents by Caprylic acid. Poultry Science Association, 14(1), 122-125.

Wehling, J., Volkmann, E., Grieb, T., Rosenauer, A., Maas, M., Treccani, L., Rezwan, K. (2013). A critical study: Assessment of the effect of silica particles from 15 to $500 \mathrm{~nm}$ on bacterial viability. Environmental Pollution, 176, 292-299.

Weiss, J., Gaysinsky, S., Davidson, M., McClements, J. (2009). Nanostructured encapsulation systems: food antimicrobials. In IUFoST world congress book: Global issues in food science and technology, 425-479.

Zhang, M., Yang, F., Pasupuleti, S., Oh, J.K., Kohli, N., Lee, I.S., Perez, K., Verkhoturov, S.V., Schweikert, E.A., Jayaraman, A., Cisneros-Zevallos, L. \& Akbulut, M. (2014). Preventing adhesion of Escherichia coli O157: H7 and Salmonella Typhimurium LT2 on tomato surfaces via ultrathin polyethylene glycol film. International Journal of Food Microbiology, 185, 73-81. 